\title{
A intervenção do psicólogo em CONTEXtos de EduCAÇão especial na gRANDE FLORIANÓPOLIS
}

The intervention OF THE PSYCHOLOGIST IN SPECIAL EDUCATION CONTEXTS IN GREATER FLORIANOPOLIS

\author{
Laura Kemp de MATTOS ${ }^{1}$ \\ Adriano Henrique NUERNBERG ${ }^{2}$
}

\begin{abstract}
RESUM O : a educação especial tem sido um contexto de inserção do psicólogo na área educacional. À luz das políticas de inclusão vigentes, a atuação do psicólogo se volta à promoção de práticas educacionais que favoreçam a partici pação eaprendizado de todos os alunos. A formação de profissionais na área da educação demanda o estudo das necessidades sociais que irão atender. Somente a partir de dados concretos acerca do contexto e das possi bilidades de intervenção pode-se identificar os conhecimentos que deverão ser ensinados. Entretanto, são raros os estudos que investigam as formas contemporâneas de intervenção da psicologia na educação especial. Assim, reunir dados sobreessa atuação permiteinstrumental izar a reflexão sobrea formação em psicologia educacional. Esse trabal ho éresultado de uma pesquisa qual itativa eexploratória que objetivou descrever as características da atuação de psicólogos da Grande Florianópol is vinculados à instituições de educação especial. Os dados foram coletados por meio de entrevistas semiestruturadas. As categorizações foram decorrentes do dial ogo estabelecido nas entrevistas e, portanto, constituídas posteriormente. A análise dos dados permitiu verificar a sobreposição das três formas de intervenção que historicamente definiram a atuação do psicólogo nessa área, a saber, a segregação, a integração e a inclusão, sendo o foco principal de atuação centrada no aluno com queixa escolar e/ ou com suspeita de deficiência intelectual. Diante disso, conclui-se esse estudo ressal tando a importância dos psicólogos refletirem sobre as implicações das políticas inclusivas para sua prática profissional.
\end{abstract}

PALAV RAS-CH AVE: educação especial; educação inclusiva; psicologia e educação; pessoas com deficiência.

ABSTRACT:In thefield of education, special education has been context in which psychologists havea place. In light of the existing inclusion policies, the work of the psychologist has been directed toward promoting educational practices that benefit all students' participation and learning. Thetraining of professionals in this educational area demands studying the social needs that will be encountered. The only way to identify what kinds of knowledge should be taught is to obtain tangible data about the context and the intervention possibilities. N evertheless, few studies have been carried out to investigatecontemporary forms of psychological intervention in special education. Thus, gathering data about this issuecontributes as a basis on which to build reflection and understanding for professional preparation in educational psychology. This articleis the result of qualitative and exploratory research designed to describe the procedural characteristics of psychologists

\footnotetext{
${ }^{1}$ Mestranda do Programa de Pós-graduação em Psicologia da Universidade Federal de Santa Catarina. kemp.laura@gmail.com

${ }^{2}$ Professor do Departamento dePsicologia da UniversidadeFederal deSanta Catarina. adrianoh@cfh.ufsc.br Subvenção: FUN PESQUISA / UFSC
} 
working in special education institutions in Greater Florianopolis. The data was collected through semistructured interviews. The categorization was derived from the exchanges established during the interviews and were therefore constituted at a later moment. The data analysis enabled us to perceivean overlap of three intervention forms that historically define the psychologists' procedure in this area, namely, segregation, integration, and inclusion, with the main procedural focus being on the student with a school grievanceand/ or suspected of having an intellectual disability. Based on thesefindings, this paper concludes by highlighting theimportance of psychologists reflecting on theimplications of inclusivepolicies in their professional practices.

KEYWORD S: Special Education; Inclusive Education; Psychology and Education; People with Disabilities.

\section{InTRODUÇão}

A formação de profissionais na área da saúde e educação demanda o estudo das necessi dades sociais as quais irão atender, bem como das condições de trabal ho. Somente a partir de dados concretos acerca do contexto e das possibilidades de intervenção pode-se identificar os conhecimentos que deverão Ihes ser ensinados, tanto na formação inicial, quanto na continuada.

Nesseâmbito, a formação do psicólogo no Brasil tem acompanhado as constantes mudanças socioculturais da sociedade, do mercado de trabalho e da Ciência. Com as novas Diretrizes Curriculares Nacionais para os Cursos de Psicologia (BRASIL, 2004), proporcionou-se também um ganho em termos de flexibilidade e inovação, permitindo aos projetos pedagógicos dos cursos maior capacidade de incorporar as demandas recentes de conhecimentos para intervenção profissional. A construção denovos currículos, contudo, tem enfrentado diversas dificuldades uma vez que implica a mobilização de barreiras conceituais epolíticas que se col ocam diante do esforço de renovação dos espaços formativos.

Esse impasse se soma à escassez de estudos referentes à formação do psi cólogo, como fatores fundamentais para implementar as inovações necessárias. A carência de pesquisas na área é apontada como grande dificuldade para o incremento dessa formação (WITTER; FERREIRA, 2005). A ssim, reunir dados sobre a atuação do psicólogo permite engendrar mel horias nesse processo.

A esse respeito vale destacar contribuições de autores como: Chacon (2004) que discute a formação do psicólogo para trabalhar com pessoas com necessidades especiais, Júnior (2007) e N eto ePenna (2006) quediscutem aspectos éticos da formação, Simão (2007) que investiga as características da atuação e profissão, Ferreira (2007) que discutea razão da existência detantas "psicologias", Paparelli e N ogueira-M artins (2007) que investigam a formação do psicólogo na perspectiva dos alunos e Júnior (1999), quediscuteas novas Diretrizes Curriculares para os cursos degraduação em psicologia, entre outras questões.

No quetangeà participação depsicólogos naárea educacional no Brasil, embora tenha havido um significativo crescimento nas últimas décadas quando comparada à área clínica, ainda está muito distante da real idade vivida em outros 
países com tradição em pesquisas e intervenção na área (WITTER et al., 2005). A realidade nacional é que o psicólogo escolar/ educacional ainda está buscando legitimar seu espaço no contexto educacional, a despeito de seu lugar no campo da Saúde já estar bem mais consolidado.

O psicólogo escolar historicamente enfocou o aluno considerado desviante da norma, visando melhorar o processo de ensino aprendizagem e auxiliar na composição de classes homogêneas. N essa lógica deculpabilização do fracasso escolar, o maior peso recai sobre o indivíduo e sua família, sendo as diferenças individuais concebidas de modo desconectado da organização do sistema social epolítico (ANDRA DA, 2005; MICHELS, 2005).

A tualmente a implementação das políticas de educação especial na perspectiva inclusiva tem trazido novos desafios para as práticas profissionais do psicólogo no contexto escolar e educacional. Mesmo o processo de avaliação psicológica se reestrutura com esse processo no sentido decomprometer o contexto institucional no fornecimento dos sistemas de apoio resultando, por sua vez, em novas perspectivas de participação do psicólogo na educação de pessoas com deficiência. Os documentos atuais mais importantes sobre classificação e diagnóstico da deficiência já incorporam esse viés sociológico e político (DINIZ, 2007; AAM R, 2006). N esseínterim, o foco da intervenção da psicologia desloca-se progressivamente do enfoque clínico e individual para o enfoque social e institucional.

Não obstante, a psicologia como ciência e profissão muito ainda pode contribuir para pensar estratégias outras deatenção eatendimento dos alunos com deficiência nos diferentes níveis de ensino, engendrando ações mais focadas nas instituições escolares e em seus processos interativos, superando enfoques individualistas e restritos ao modelo médico da deficiência (OLKIN; PLEDGER, 2003).

Na educação especial, hoje compreendida como uma modalidade do sistema educacional, os psicólogos contam com um significativo reconhecimento profissional como especialistas do desenvolvimento humano. Contudo, raros são os estudos que investigam as formas contemporâneas de atuação do psicólogo nesse contexto (ANACHE, 2007) por serem relativamente recentes as políticas nacionais de educação especial na perspectiva inclusiva. Dentreeles, destaca-seo artigo de A nache (2005), discutindo aspectos históricos da interface psicologia e educação especial e, mais recentemente, a pesquisa do CFP (2008) mapeando em termos descritivos a atuação profissional dos psicólogos nos programas e instituições relacionadas às políticas de educação inclusiva.

Há estudos que caracterizam a atuação dos psicólogos em contextos de educação especial, dentre eles cabe ressaltar o estudo exploratório de M endonza (1997) quereal izou um levantamento das características da intervenção dos psicólogos escolares quetrabal ham com al unos com deficiência em M ato Grosso do Sul. Outros artigos também merecem destaque, como o relato de pesquisa de Gomes e González 
Rey (2008) sobrepsicologia eindusão eo relato deuma vivência prática deCavanelas (2000), psicól oga em uma instituição voltada para pessoas com deficiência.

Nessesentido, conhecer as características da intervenção dos psicólogos em instituições de educação especial eo impacto das políticas de inclusão escolar em suas práticas profissionai s éfundamental para a avaliação desse processo com vistas à identificação de necessi dades de incremento da formação dos psicólogos, demodo a ampliar a responsabilidade social eos direitos humanos (SI LVA , 2005). Com esse estudo espera-se fornecer subsídios a essa formação na perspectiva inclusiva, de modo a possibilitar a identificação dos avanços eas lacunas existentes na prática desse profissional.

\section{Método}

A atual realidade científica é marcada pela cisão entre investigação e intervenção, o que leva ao distanciamento entre a mudança e o conhecimento, na medida em quemuitos pesquisadores não utilizam os resultados desuas pesquisas para promover mel horias em suas sociedades. N esseâmbito, esse estudo pretende ser um agente de transformação social, subsidiando a formação profissional em psicologia (GIL, 1999).

A natureza dessa pesquisa é qualitativa e exploratória, pois tem por objetivo proporcionar uma caracterização da intervenção do psicólogo na educação especial numa perspectiva inclusiva (GIL, 2002). O projeto de pesquisa que pautou esseestudo foi aprovado pelo Comitêde Ética na Pesquisa em Seres Humanos da UFSC, pelo código FR-224703.

Para a caracterização que essa pesquisa pretendeu realizar foram selecionados para entrevista 12 psicólogos inseridos nas principais fundações, centros de reabilitação e associações, em geral mantidas pela sociedade civil em parceria com o Estado e M unicípios, às quais se vinculam escolas que atendem aos al unos com deficiência da GrandeFlorianópolis.

Por meio de carta deapresentação dos pesquisadores e do projeto, foi realizado o primeiro contato com as instituições. Em seguida à autorização foram feitos contatos tel efônicos com os psi cólogos, para agendar os encontros. N esses encontros objetivou-seapresentar os pesquisadores, explicar o objetivo da pesquisa eidentificar seos entrevistados dispunham-se a participar.

Para o levantamento e análise dos dados foram utilizados: roteiro de entrevista, termo de consentimento, gravador digital, pilhas, fol has em branco, caneta, lapiseira e computador. A s entrevistas, real izadas entre os meses deabril e dezembro de 2008, foram feitas no próprio local de trabalho dos sujeitos com duração média de uma hora emeia, sendo todas gravadas etranscritas com prévio consentimento do sujeito entrevistado. Os resultados foram obtidos a partir do entrelaçamento das diferentes informações, organizadas e classificadas em categorias deanál ise, valorizando informações qual itativas equantitativas. 
A coleta dedados foi realizada por meio deentrevista semiestruturada. O roteiro da entrevista foi constituído por 12 questões abertas e 10 questões fechadas, as quais objetivaram identificar os dados pessoais, as características do contexto em questão e as condições de trabalho, as características da atuação profissional, al ém da relação entrea atuação eformação acadêmica.

Considera-se que a entrevista, numa pesquisa qualitativa, não se constitui como um instrumento fechado, mas sim num diál ogo entre pesquisador e pesquisado, entretecidos ao contexto social (GONZÁLEZ REY, 2002). Nesse sentido, pretendeu-seinvestigar as condições concretas quepossi bilitam o exercício profissional do psicólogo inserido em contextos de ensino numa perspectiva inclusiva.

\section{Resultados}

A idade média dos psicólogos entrevistados é de 39 anos, variando entre 54 e 26 anos. A mai oria deles édo sexo feminino, apenas dois psicólogos do sexo masculino participaram da pesquisa. Dentre os participantes desse estudo oito concluíram a graduação em psicologia em instituições privadas de ensino superior e quatro em instituições públicas. Tais dados coincidem com o levantamento realizado pela Associação Brasileira de Psicologia Escolar e Educacional - ABRAPEE, sobre as características dos psi cólogos que atuam em políticas públicas educacionais (PROEN ÇA; SI LVA , 2009). Esses resultados também são similares aos apontados por Mendoza (1997), Rosas, Rosas e Xavier (1988) e pelo CFP (1994) quando descrevem características de sexo, idade e formação dos psicólogos brasileiros.

No que tange às características do contexto, apesar de nove (75\%) dos entrevistados serem contratados como psicólogos, com carteira assinada, três (25\%) trabal ham como prestadores de serviços, indicando uma precariedade nas formas de contratação. A carga horária de trabal ho para a mai oria dos entrevistados éde 40 horas semanais. Dentreeles sete profissionais (58\% dos informantes da pesquisa) trabalham como psicólogos na área de educação especial há menos de seis anos. Além deatuarem em instituições deeducação especial, seispsicólogos entrevistados (50\%) atendem também em consultórios particulares e dois trabal ham em outras áreas, a saber, um deles lecionando artes marciais eo outro preferiu não especificar a atividade.

Os dados foram analisados com baseem duas categoriasa priori, quais sejam atuação eformação profissional. Os demais resultados foram obtidos a partir do entrelaçamento das diferentes informações, organizadas e classificadas em categorias de anál ise a posteriori, pois foram decorrentes do dialogo estabelecido nas entrevistas e, portanto, constituídas posteriormente para análise de conteúdo, conformeFranco (1994). 


\subsection{A tuação Profissional}

Todos os entrevistados trabalham em equipes multidisciplinares, organizadas por meio dereuniões semanais compostas geral mentepel os seguintes profissionais: pedagogo, médico, fisi oterapeuta, terapeuta ocupacional, professor de educação especial, assistentesocial epsicólogo.

As principais atividades desenvolvidas no cotidiano de trabal ho são apresentadas na figura 1. As demandas das instituições em relação ao trabal ho dos psicólogos entrevistados são bem distintas entre si, embora a orientação/ educação de pessoas com deficiência ea atuação junto às famílias sejam atividades desenvolvidas por quase todos os entrevistados (92\%). A avaliação psicológica, orientação/ educação sexual eintervenções com a equipetécnica apareceram como realizadas por 10 dos informantes (cerca de 83\%). Tais resultados são próximos aos apresentados por M endonza (1997) em estudo semel hante realizado no Estado deM ato Grosso do Sul.

Destaca-se também na Figura 1 a assistência psicológica com al unos realizada por nove profissionais (75\%), além da orientação psicoeducacional aos professores, atendimento de emergência, visitas domiciliares e assistência psicológica com professores realizadas por oito entrevistados (cerca de67\%). Outra atividade quefoi mencionada por seteentrevistados (aproximadamente $58 \%$ ) foi a elaboração, avaliação e desenvolvimento do projeto pedagógico, como visto no gráfico a seguir.

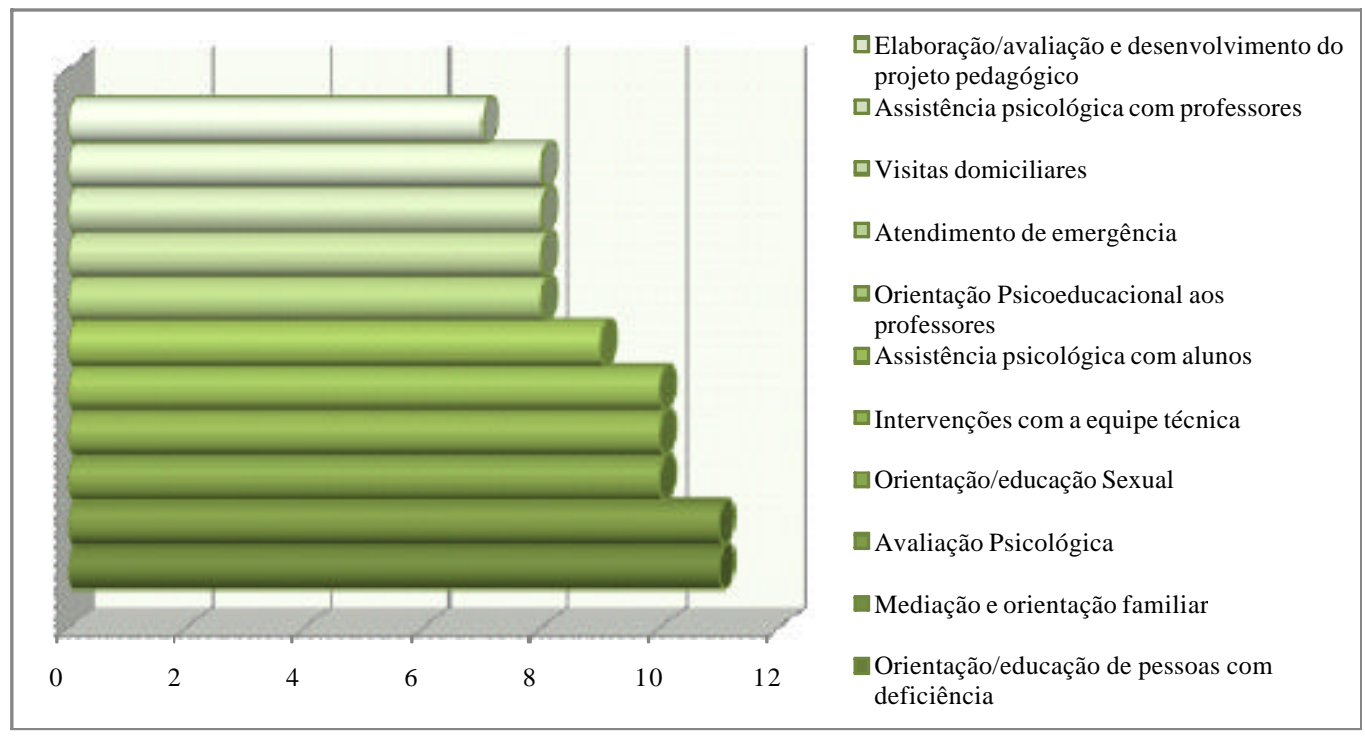

Figura 1- A tuação profissional . 
A lém do teste de inteligência, boa parte dos profissionais real iza uma entrevista com a família para identificar aspectos referentes à comunicação, cuidados pessoais, vida familiar, habilidades sociais, auto-gestão, saúde, segurança, habilidades cognitivas ecomportamentos do aluno. N essecaso, observa-setambém como ele está interagindo com o meio avaliando o comportamento adaptativo, componenteinserido no momento que vigoravam as políticas deintegração, tendo sido proposto por meio dos parâmetros de avaliação da $A A M R^{3}$ na década de 60 . A pós essa avaliação, todos os profissionais da equipe diagnóstica ${ }^{4}$ reúnem-se para estudo do caso efechamento do diagnóstico.

A seguir apresenta-se a Figura 2, relativa aos dados sobre outras atividades menos destacadas dos psicólogos informantes dessa pesquisa:

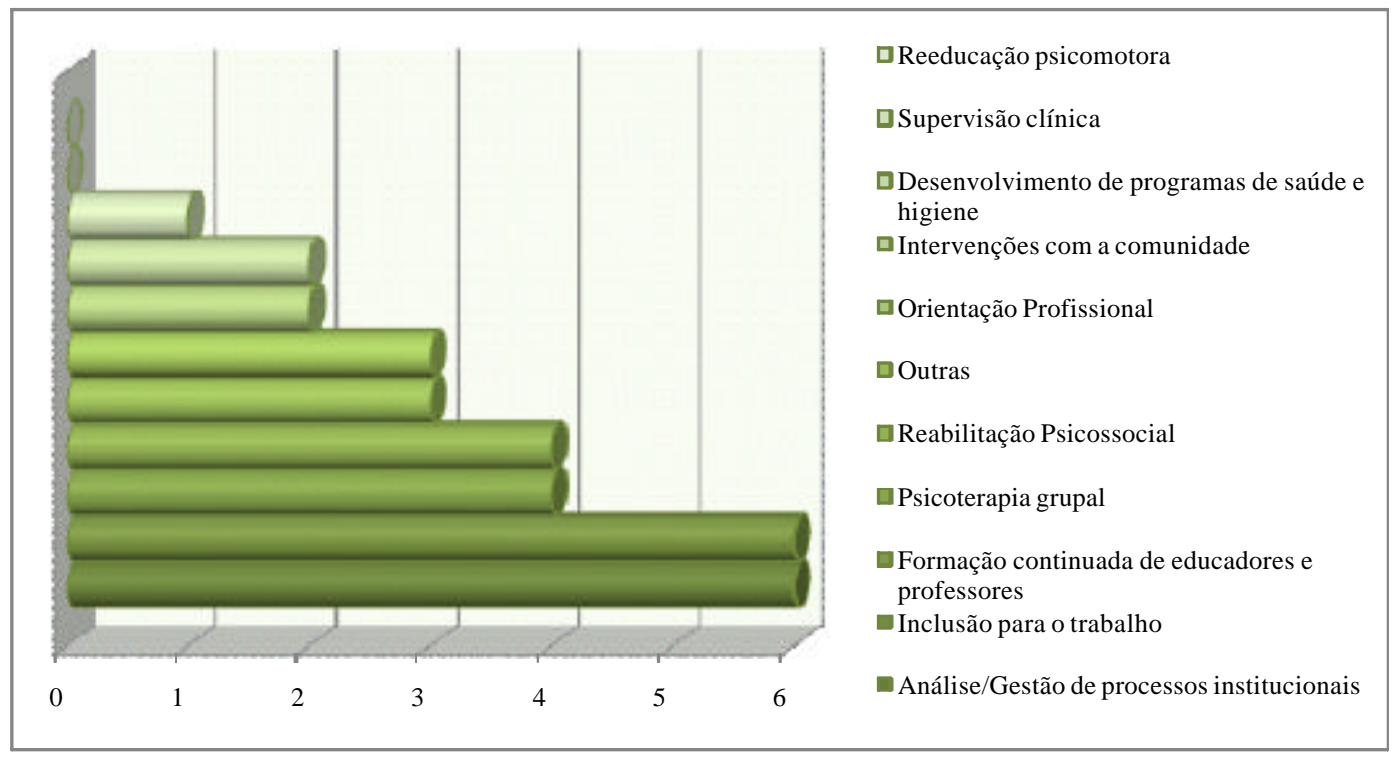

Figura 2- A tuação profissional .

A inclusão para o trabalho eanálise/ gestão deprocessos institucionais, contudo, são realizadas por seis (50\%) psicólogos. A psicoterapia grupal e a formação continuada deeducadores eprofessoressão real izadas apenas por quatro

\footnotetext{
${ }^{3}$ A ssociação A mericana de Retardo Mental, hoje, chamada A ssociação A mericana de Deficiência Intelectual, principal instituição internacional naárea, definindo os parâmetros dedefinição, classificação eencaminhamento da deficiência intelectual.

${ }^{4}$ Psicólogos, médicos, fisioterapeutas, pedagogos, etc. de acordo com a necessidade.
} 
entrevistados (cerca de 33\%). Esses dados apontam a necessidadeem (re)definir o objeto e a demanda de intervenção do psicólogo, tendo em vista as políticas de inclusão. A atual política de educação especial ressalta a necessidade do trabalho interdisciplinar ea importância da formação inicial econtinuada dos professores. N esseâmbito, abre-seespaço para a intervenção da psicologia que pode colaborar para essa formação (PRIETO, 2005).

A reabilitação psicossocial, orientação profissional, intervenções com a comunidade, desenvolvimento de programas de saúde e higiene foram assinalados por menos de $25 \%$ dos informantes da pesquisa. Nenhum dos psicólogos entrevistados real iza reeducação psicomotora enem supervisão clínica, evidenciando uma atuação mais vol tada à área educacional .

A Figura 3, por sua vez, apresenta quem são as pessoas que usufruem dos serviços dos psi cólogos entrevistados. Todos afirmam atender os al unos do ensino especial edo ensino fundamental. Em seguida, os al unos do ensino infantil, do ensino médio e professores(as) são atendidos por 11 psicólogos (aproximadamente92\%). Cumpre destacar queesses professores são em sua maioria do ensino especial enão da rederegular deensino. São atendidos pel os psicólogos geralmente quando enfrentam alguma dificuldade.

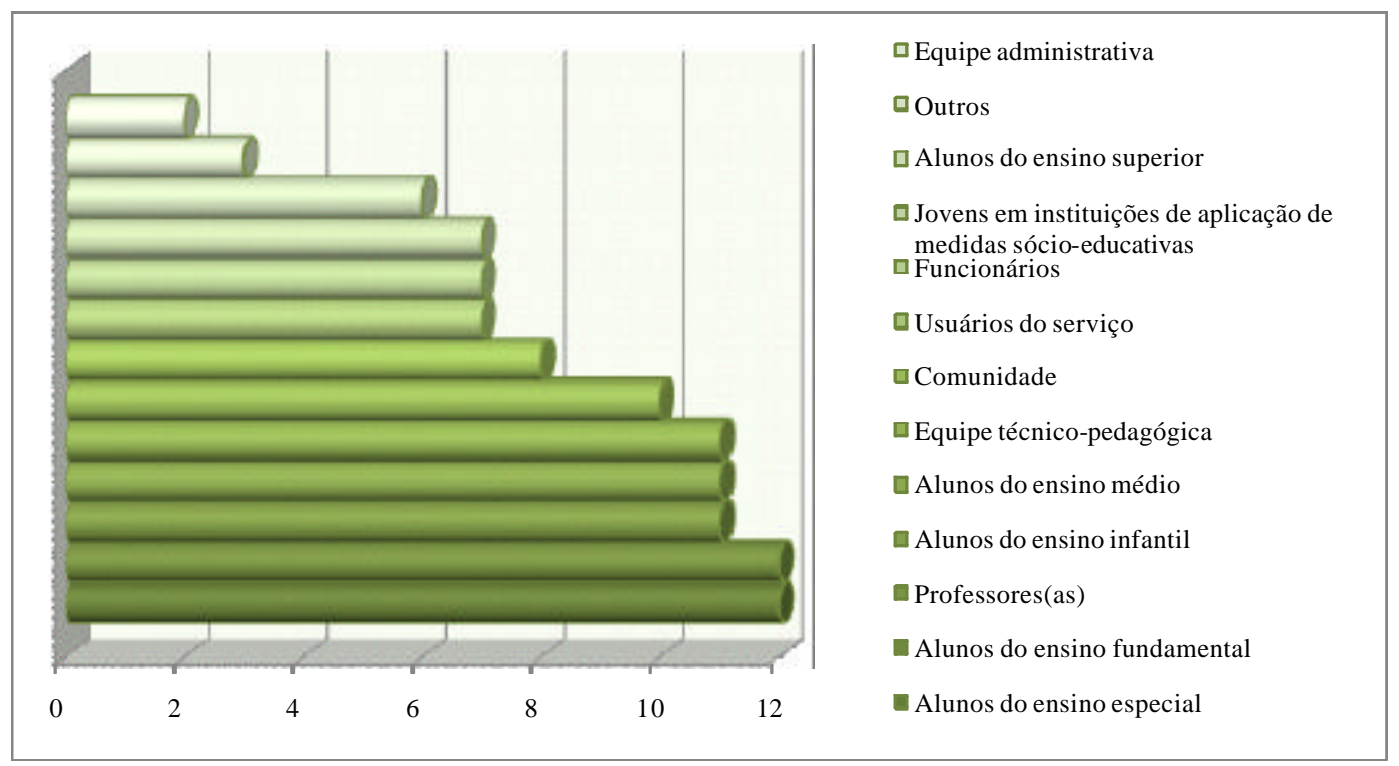

Figura 3- Quem usufrui de seus serviços como psicólogo educacional? 
Nota-se também que 10 entrevistados (cerca de $83 \%$ ) atendem a equipe técnico-pedagógica, principal mente das instituições de educação especial. A ções focadas na comuni dade são real izadas por oito profissionais (aproximadamente $66 \%$ os informantes da pesquisa). Os usuários do serviço, funcionários ejovens em instituições de aplicação de medidas socioeducativas são atendidos por sete profissionais (cerca de 58\%). Alunos do ensino superior são atendidos por seis psicólogos (50\%) e a equipe administrativa, entre outros foram apontados por menos dequatro profissionais.

Os principais instrumentos utilizados pelos psicólogos estão relacionados na Figura 4. Destacam-seas entrevistas eos manuais de diagnóstico como os mais usuais. Os testes psicológicos utilizados pelos entrevistados são: Escal a de Maturidade Mental de Columbia - CMMS, Escala de Inteligência de Wechsler para Crianças - WISC III, Perfil Psicoeducacional Revisado - PEP-R, Matrizes Progressivas de Raven e técnicas projetivas, como a técnica do desenho da família, por exemplo.

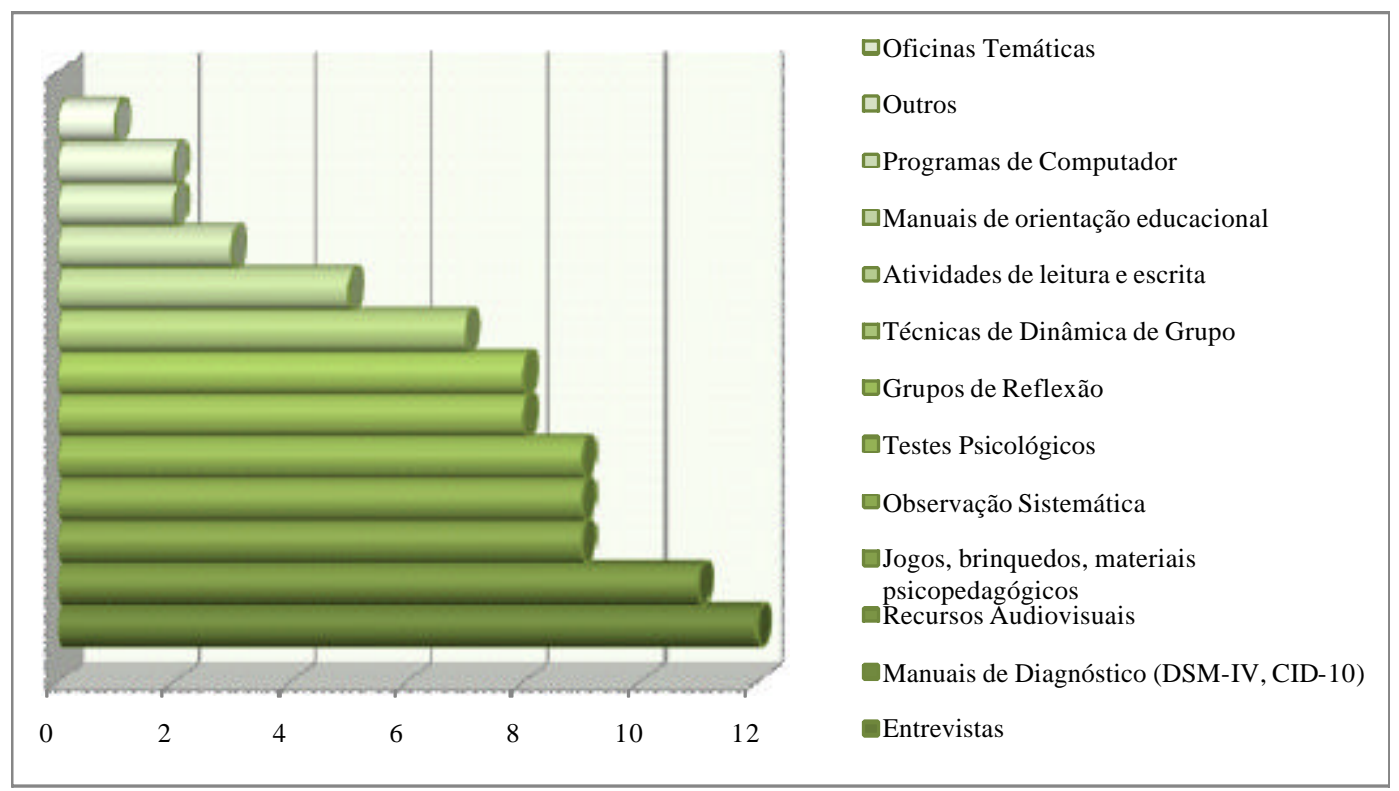

Figura 4 - Instrumentos utilizados no cotidiano de trabal ho.

Os principais desafios vivenciados no cotidiano de trabalho, por sua vez, foram: atender a família, trabalhar com os familiares a aceitação e a superproteção, minimizar preconceitos por meio de esclarecimentos, implantar uma cul tura de estudos na instituição, desenvolver estudos e pesquisas na área da educação especial para desenvolver metodologias, ajudas técnicas, recursos 
adaptados etc., trabal har as dificuldades deensinagem no quetangeaos professores do ensino regular, al ém de incluir de fato essas crianças, como exemplificado por uma das entrevistas a seguir: “O maior desafio étentar que seja feito realmente (...) o que precisa ser feito (...) no ambiente escolar, na família, para que ele possa ter uma melhor qualidade de vida. Porque se ele tiver os apoios necessários, a deficiência acaba diminuindo muito" (SUJEITO 5).

Foram relatadas também dificuldades de natureza formativa, institucional e financeira para o exercício de práticas profissionais outras que contribuam para as políticas de inclusão escolar. Os entrevistados também apontaram obstáculos para o exercício profissional como a estrutura física limitada, fal ta de apoio a pesqui sas, dificuldades com relação ao vínculo com a instituição e falta de suporte institucional, por exemplo, que contribuem para a precarização do trabal ho do psicólogo.

\subsection{Formação Profissional}

No que concerne ao referencial teórico e metodológico que subsidia a atuação dos psi cólogos entrevistados, a teoria sistêmica e a psicologia históricocultural de Lev Vygotski foram os mais citados. Os entrevistados relataram agregar diversas teorias à sua prática. Foram também mencionadas a abordagem cognitiva, a comportamental, a psicanálise, a psicodinâmica, a teoria da gestalt, a teoria humanista e a psicobiologia. Foram citados autores como: "Vygotski, Piaget, Wallon, Freud, Melanie Klein, A na Bock, Ciampa, Ronal do Yudi" (SUJEITOS 10, $11 \mathrm{E} 12)^{5}$. E também “Luria, Leontiev, Vygotski, Rossi, Erikson” (SUJEITO 2). Esses dados apontam que os teóricos da área do desenvolvimento e aprendizagem tem si do os mais importantes para esses profissionais, embora também se perceba que a identidade do psicólogo Escolar/ Educacional está muito relacionada às diferentes correntes clínicas da psicologia.

Com relação à formação inicial oito entrevistados (cerca de 67\%) afirmaram não terem apreendido o conhecimento necessário para a atuação na educação especial, caracterizando, por sua vez, uma dificuldade encontrada no contexto da formação profissional. Para alguns dos entrevistados "o que aprendemos na universidade auxilia no nosso cotidiano de trabalho, mas não éo suficiente para dar conta da demanda" (SUJEITOS 10, 11E 12). Outro relato nesse sentido aponta lacunas na formação, mas enfatiza que "essa falta foi compensada pela busca por conta própria, participando de congressos, pesquisas e grupos de estudos" (SUJEITO 3). A penas dois profissionais afirmaram que a formação deu bastante subsídio e também dois entrevistados afirmaram que nada do que foi aprendido é utilizado no cotidiano de trabal ho como psicólogos na educação especial. ${ }^{5} \mathrm{~A}$ entrevista foi realizada em conjunto com os sujeitos 10,11 e12. A penas al gumas questões foram respondidas
individual mente. 
A cerca desta real idade cumpre resgatar os resultados da pesquisa de Chacon (2004), queanal isa aspectos da formação de recursos humanos em educação especial, problematizando o impacto da Recomendação M inisterial n. 1.793/ 94, que propõe a inserção da temática de inclusão das pessoas com deficiência, no âmbito dos cursos de formação em psicologia, pedagogia e licenciaturas. Se conforme o autor, a maior dos cursos de psicologia possui espaço dedicado para essa temática, nossos dados sugerem haver problemas na qualidade da formação proporcionada.

No quetangeà pós-graduação, dois psicólogos (menos de 17\%) fizeram mestrado. Com relação à formação continuada ${ }^{6}$ nove entrevistados (75\%) fizeram cursos de especialização na área de atuação. Foram citados cursos tais como: educação especial, retardamento mental, estimulação essencial, educação inclusiva egrupos deestudo. Outros três profissionais não fizeram nenhuma pós-graduação.

Para os psicólogos entrevistados existe uma relação direta do seu trabalho com as políticas públicas de Inclusão Escolar. Contudo, parte dos informantes questionou a política de Educação Especial proposta pelo MEC, pois suas diretrizes a inclusão de todos os alunos no ensino regular, independente do grau de comprometimento. Na Política de Educação Especial de Santa Catarina (2006), contudo, os al unos menos comprometidos podem ir para a rederegular de ensino e os mais severamente comprometidos podem continuar sendo atendidos apenas por instituições especializadas, cabendo essa decisão à família. Em todo caso, afirmam que atual mente estar na rede regular de ensino é um direito e cabe ao Estado garanti-lo.

\section{Discussões}

Os resultados apontam a permanência de práticas consideradas tradicionais nessecampo, especial menteno tocanteaos procedimentos deavaliação psicológica (MENDOZA, 1997). Nesse âmbito, cabe destacar as principais características da avaliação descritas pel os profissionais quea realizam. A finalidade da avaliação ébasicamenteverificar as condições da "inteligência dessesujeito" (sic). O objetivo final é dizer como é que está o "nível desse sujeito" (sic), seé realmente um al uno com deficiência mental eem qual grau, a saber, leve, moderado, severo e profundo. O olhar da psicologia é mais voltado para a deficiência intelectual no processo de diagnóstico, prática que vem marcando a profissão desde as arcaicas políticas desegregação, quando a atuação do psicól ogo restringia-seao processo de aval iação do grau deincapacidade, focando apenas a deficiência no psicodiagnóstico do sujeito. Assim era a perspectiva de atenção às pessoas com deficiência nesse período que visava classificar os sujeitos para formar classes homogêneas. Nesse sentido, os depoimentos dos profissionais apontam fortes etardias influências dessa

\footnotetext{
${ }^{6}$ Outros cursos de especial ização também foram mencionados por quatro psicólogos (33\%) como: formação em sistêmica, Iudoterapia, psi coterapia analítica eatenção a vítimas de violência doméstica.
} 
perspectiva no processo deaval iação psicológica, cumprindo o papel deatendimento a demandas de ordem institucional.

A respeito dos encaminhamentos, temos um fato já bem descrito na literatura (BUENO et al., 2001; MACHADO, 2007; SOUZA, 2007a). O trecho transcrito abaixo de umas das entrevistas sintetiza bem o papel da escola na produção da queixa escolar em rel ação aos sujeitos encaminhados:

Podeser dediferentes formas (...) o queémais usual, principalmentena área da deficiência mental, não quando tem síndrome porquequando tem síndrome, por exemplo, na síndrome de Down logo se percebe, mas a deficiência mental geralmenteéidentificada na escola. Então o professor muitas vezes identifica ou acredita queaquela criança édiferente por al gum motivo (...). No caso desuspeita deuma deficiência eleéchamado para fazer uma avaliação (SUJEITO 2).

O excesso de encaminhamentos vindos da escola regular foi apontado pelos entrevistados, como no trecho a seguir: "A demanda é enorme. A escola encaminha (...) soli cita avaliação, mas a maioria deles (...) de 15 ficam só dois aqui. A gentefaz uma vez por semana avaliação etem lista de espera. A maioria não é aluno pra cá" (SUJEITO 11). Conforme os depoimentos colhidos, a equipe de avaliação precisaria ter mais profissionais para atender à demanda, uma vez quea pressão institucional para a avaliação dos sujeitos impõel imitações ao trabal ho do psi cólogo. Essa carência restringea atuação no campo da avaliação, inviabilizando a reflexão sobre as práticas profissionais, a partir das políticas de inclusão escolar. A atuação do psicólogo escolar e educacional sobre a queixa escolar permanece com foco da atenção no al uno e não nos contextos institucionais, bem como este profissional acaba reforçando o viés clínico patologizante que essa lógica institucional historicamente configura (SOUZA, 2007b; MA CHADO, 2007).

A análise dos sujeitos pelo viés normal/ anormal, muitas vezes exclui a complexidade das diferenças que os constituem. A valiar o sujeito pode ser uma prática que não se reverte em ações concretas para melhoria das condições de aprendizagem e inclusão dos alunos uma vez que não subsidia a intervenção educacional e desconsidera a história de produção da queixa escolar, selando destinos confinados à exclusão escolar. Nesse sentido, as diferenças individuais devem ser compreendidas interligadas às oportunidades sociais, políticas e educacionais. Os múltiplos contextos e dinâmicas institucionais precisam ser considerados na aval iação psi cológica (ANDRA DA, 2005; A MIRA LIAN, 1986).

A avaliação psicológica vem sofrendo um processo de transformação e os dados obtidos apontam essa mudança. Ao mesmo tempo em que o processo de avaliação começa a inserir dados do contexto do aval iado, há ainda fortes influências do model o médico e clínico tradicional, orientando a prática de psicodiagnóstico de uma maneira reducionista. Diagnosticar, classificar e encaminhar tem sido atividades que demarcam a atuação do psicólogo na educação, no entanto, esse profissional deveevitar cair na lógica da estigmatização ebuscar definir os sistemas 
de apoio necessários, que gerem a melhoria da atenção educacional às pessoas com deficiência.

Assim, o processo deavaliação psicológica deveser reestruturado a partir da Classificação Internacional de Funcionalidade, Incapacidade eSaúde- CIF, que se articula com o modelo social de deficiência, cujo argumento central aponta a opressão social, como causa das desvantagens vividas por essegrupo social (DINIZ, 2007; AAMR, 2006). Para tanto, a deficiência não pode mais ser definida apenas a partir do modelo biomédico como uma condição meramente biológica, mas como o produto deuma interação do sujeito com seu contexto social. A aval iação psicológica deve, portanto, produzir dados sobreas barreiras existentes no contexto social, para fornecer os sistemas de apoios necessários enfatizando as “possibilidades e não só das limitações dosalunos" (SUJEITO 11).

Alguns psicólogos entrevistados que têm visão crítica percebem que muitas barreiras estão presentes no cotidiano escolar. Dentre as dificuldades apontadas por um entrevistado estão as "dificuldades de ensinagem e recursos adaptados, põem sempre a culpa no aluno e muitas vezes a dificuldade é do professor" (SUJEITO 12). Nesse âmbito, cabe a psicologia atuar no sentido da promoção da cidadania, mediando os processos de inclusão escolar, visando reduzir as barreiras atitudinais vivenciadas pelos alunos com deficiência que são, em sua maioria, sofrimentos desnecessários, decorrentes de preconceitos e estigmas (VIVARTA, 2003).

A despeito de haver evidências da consciência crítica destes profissionais com relação às limitações de sua prática, cumpre afirmar que as características desua atuação estão na maior partedas vezes em antagonismo com princípios inclusivos al mejados nas políticas educacionais nacionais. Uma vez que sua atuação recai predominantemente sobre os alunos, com um enfoque tímido em relação às questões institucionais e à produção da queixa escolar, pode-se também considerar tais práticas em dissonância com a literatura atual da área (SOUZA, 2007a; SOUZA , 2007b; MACHADO, 2007; A LMEIDA, 2006).

\section{C ONCLUSÕes}

A análise dos dados permitiu verificar a sobreposição das três formas de intervenção que historicamente definiram a atuação do psicólogo nessa área, a saber, a segregação, a integração e a inclusão (BEYER, 2006), sendo o foco princi pal de atuação centrada no al uno com queixa escolar e/ ou com suspeita de deficiência intelectual.

A avaliação psicológica ainda é pautada no diagnóstico psicológico clínico tradicional, a partir de testes e observações isoladas do contexto, embora se considere relevante os dados relativos à relação do sujeito com a família e comunidade, os quais indicam mudanças nessa prática. Consideramos que a avaliação psi cológi ca éum procedimento necessário à intervenção, como processo 
deidentificação defatores psicológicos esociais ededados sobreo desenvol vimento e aprendizado que subsidiem as práticas educacionais a serem propostas aos sujeitos. Por isso, os resultados nos levam a refletir sobre essas práticas, pautadas por princípios institucionais limitados à classificação de sujeitos de acordo com as incapacidades destes, reforçando assim o caráter normativo quea psicol ogia vem cumprindo historicamente.

O psicólogo como profissional, juntamente com muitos outros com os quais trabal ha, é responsável pela constituição de espaços interpsicológicos em que sentidos possam emergir, nos quais significados cristalizados sejam problematizados e avaliados quanto à adequação ao projeto político que coletivamente empreendem para, em conjunto, estabilizarem outros sentidos (ZANELLA, 2006). Assim, o processo de avaliação psicológica deve ser problematizado, de modo a se pensar sua capacidade de abranger as múltiplas variáveis constituintes da deficiência e permitir a construção de dados que subsidiem as decisões pedagógicas voltadas para as turmas em que se pratica a inclusão escolar.

A inclusão social visa à modificação da sociedade para possibilitar o desenvolvimento pessoal e social da pessoa com deficiência, garantindo possibilidades de exercício da cidadania (BRASIL, 2008). O atendimento educacional especializado é (re)organizado para apoiar o desenvolvimento dos alunos, exigindo transformações na prática profissional do psicólogo. No entanto, foi observado que o trabalho éainda focado prioritariamenteno al uno, mantendo muitas vezes uma prática excludentee individualizante.

A atuação profissional do psicólogo muito avançou nos últimos anos, com a transição do model o clínico-terapêutico para o modelo institucional, como referência para intervenção do psicólogo escolar eeducacional (M A CHADO 2007; SOUZA, 2007a; ARAÚ JO 2006). Embora o primeiro modelo ainda persista nas práticas cotidianas demuitos profissionais, já se consolidou a crítica à psicologização da aprendizagem e à culpabilização da família e do al uno em rel ação ao fracasso escolar (NEVES, 2009). A o mesmo tempo, estamos em um momento de construção de referências ${ }^{7}$ para a intervenção do psicólogo nesse contexto, nas quais se considere a dinâmica institucional das escolas e a complexidade do fenômeno educacional (SOUZA, 2007b).

Para tanto, os resultados levantados fornecem subsídios à formação em psicologia, contribuindo para possibilitar outros avanços na prática desse profissional. N ovas pesquisas em âmbito nacional são indispensáveis para conhecer as características daintervenção dos psicólogos nas instituições deeducação especial

\footnotetext{
${ }_{7}$ Vale lembrar as ações do Conselho Federal de Psicologia, instituindo em 2008 o "A no da Psicologia na Educação", quando os psicól ogos foram convidados a estabelecer princípios para intervenção sobreas principais questões da educação no mundo contemporâneo.
} 
na perspectiva inclusiva. Conhecer essa real idade de trabal ho éfundamental para a ampliação do conhecimento, promovendo deste modo a inclusão no debate da real contribuição do psicólogo na educação especial.

O psicólogo pode atuar no cotidiano da inclusão escolar criando em parceria com os educadores novas formas de mediação qual ificada, visando superar as barreiras vivenciadas pelo aluno com deficiência e os demais envolvidos no contexto escolar. Dentre essas barreiras, aquel as de natureza atitudinal ${ }^{8}$ merecem especial enfoque pelo psicólogo. Sua intervenção sobre preconceitos, estigmas e mitos que atuam sobre as pessoas com deficiência e marcam suas trocas sociais negativamente devese constituir uma das principais características deseu trabalho na educação especial numa perspectiva inclusiva (AMARAL, 1998).

N esseâmbito, recomenda-se o uso de estratégias de intervenção sobre o coletivo das instituições escolares, por meio de formas de abordagem que val orizem os saberes dos educadores e permitam a el es assumir o protagonismo da inclusão escolar. Uso de recursos como grupos focais, dinâmicas de grupo e debates que priorizem a troca de experiências podem ser exemplos de práticas que seguem uma direção mais próxima aos princípios inclusivos (MARTINEZ, 2005). Contudo, alerta-se para o fato de que, mais importante do que as estratégias utilizadas, é a postura do psicólogo. Esse profissional não deve ocupar o lugar social do especialista que detém um dado saber-poder exclusivo em torno do desenvolvimento e educação do aluno com deficiência, mas propor a responsabilização progressiva dos professores pela educação de todos os al unos, independente de sua condição.

\section{ReferênCIAS}

ALMEIDA, S.F.C. Psicologia escolar: ética ecompetências na formação eatuação profissional. 2ed. Campinas: Alínea, 2006.

AMARAL, L.A. Sobrecrocodilos eavestruzes: fal ando dediferenças físicas, preconceitose sua superação. In: A QUINO, J. D iferen ças e preconceitos na escola: al ternativas e práticas. 8 ed. São Paulo: Summus, 1998, p. 11-29.

AMIRA LIAN, M.L.T.M. Psicologia do excepcional. 1. ed. São Paulo: EPU, 1986.

ANDRADA, E.G.C. N ovos paradigmas na prática do psicólogo escolar. P sicologia: R eflexão e Crítica, v. 18, n. 2, p. 196-199, 2005.

\footnotetext{
8 “Barreiras atitudinais são anteparos nas relações entre duas pessoas, onde uma tem uma predisposição desfavorável em relação à outra, por ser essa significativamente diferente, em especial quanto às condições preconizadas como ideais" (AMARAL, 1998: 17).
} 
ANACHE, A .A . O psicólogo nas Redes deServiços deEducação Especial: desafios em face da inclusão. In: MARTINEZ, A.M. (org). Psicologia escolar e compromisso Social. 1 ed. Campinas: Alínea, 2005, p. 115-133.

. A pessoa com deficiência mental entre os muros da educação. In: CAM POS, H.R. (Org.). F ormação em psicologia escolar: realidades e perspectivas. 1 ed. Campinas: Alínea, 2007, p. 213-243.

ARAÚJO, M.G. O pinião depsicólogos sobreseu preparo profissional para atender as necessidades humanas básicas de crianças com deficiência mental. 2006. Dissertação (M estrado em Ciências da Saúde) - Núcleo de pós-graduação em medicina, Universidade Federal de Sergipe, Aracajú.

ASSOCIATION ON MENTAL RETARDATION (AAMR). Retardo mental: definição, classificação e sistemas de apoio. 10 ed. Porto A legre: Artmed, 2006.

BRASIL. Conselho Nacional de Educação. Câmara de Educação Superior. Institui as Diretrizes Curriculares $\mathrm{N}$ acionais para os cursos degraduação em Psicologia. Resolução $\mathrm{n}$. 8/ 2004, de 18 maio 2004, D iário O ficial da U nião, Brasília, 16 p., Seção I, 2004.

. Secretaria Especial dos Direitos Humanos. Coordenadoria Nacional para Integração da Pessoa Portadora de Deficiência. A Convenção sobre os Direitos das Pessoas com Deficiência Comentada. COR D E. Brasília, 2008, 163 p.

BEYER, H.O. Da integração escolar à educação inclusiva: implicações pedagógicas. In: BA PTISTA, C.R. et al. Inclusão e escolarização. 1 ed. Porto A legre: Mediação, 2006.

BUENO, M.T.B., SALUM E MORAIS, M.L.; URBINATTI, A.M.I. Queixa escolar: proposta de um modelo de intervenção. In: SOUZA, B.P.; SA LUM E MORAIS, M. Saúde e educação: muito prazer! 1 ed. São Paulo: Casa do Psicólogo, 2001, p. 51-68.

CAVA NELAS, L.B. Psicologia e compromisso social. Psicologia Ciência e P rofissão, v. 20, n. 1, p. 18-23, 2000.

CHACON, M.C.M., Formação de recursos humanos em educação especial: resposta das universidades à recomendação da portaria ministerial № 1.793. R evista Brasileira de E du cação Especial, v. 10, n. 3, p. 321-336, 2004.

CONSELHO FEDERA L DE PSICOLOGIA (CFP). P sicólogo brasileiro: práticas emergentese desafios para a formação. 2 ed. São Paulo: Casa do Psicólogo, 1994.

Relatório preliminar. Pesquisa: Prática Profissional dos Psicólogos em Políticas Públicas. A tuação Profissional dos Psicólogos em Programas deEducação Inclusiva. Brasília: Junho de 2008.

DINIZ, D. 0 que édeficiência. 1 ed. São Paulo: Brasiliense, 2007.

FERREIRA, A.A.L. A diferença que nos une: o múltiplo surgimento da psicologia. In: Ser na Psicologia: diálogos sobrea profissão. R evista do D epartamento de P sicologia - UFF, v. 19, n. 2, p. 477-500, Jul.-Dez. 2007.

FRA NCO, M.L.P.B. O queéanálise deconteúdo In: FRANCO, M.L.P. Ensino médio: desafios e reflexões. 1 ed. Campinas: Papirus, 1994, p. 155-180.

GIL, A.C. M étodos e Técnicas eP esquisa Social. 5 ed. São Paulo: Atlas, 1999. . Como elaborar projetos de pesquisa. 4 ed. São Paulo: Atlas 2002. 
GOMES, C.; GONZÁLEZ REY, F.L. Psicologia einclusão: aspectos subjetivos deum aluno portador de deficiência mental. Revista Brasileira de Educação Especial, Marília, v.14, n.1, p.53-62, Jan.-Abr. 2008.

GONZÁLEZ REY, F.L. Pesquisa qualitativa em psicologia: caminhosedesafios. 1ed. São Paulo: Pioneira Thomson Learning, 2002.

JÚNIOR, A.R. Das discussões em torno da formação em Psicologia às diretrizes curriculares. Psicologia: Teoria ePrática. v. 1, n. 2, p. 3-8, 1999.

JÚNIOR, N.E.C. Ética \& técnica em psicologia: Narciso e o avesso do espelho. In: Ser na Psicol ogia: diál ogos sobre a profissão. Revista do Departamento de Psicologia - UFF, v. 19, n. 2, p. 477-500, Jul.-Dez. 2007.

MACHADO, A.M. Plantão institucional: um dispositivo criador. In: MACHADO, A.M., FERNANDES, A.; ROCHA, M. N ovos possíveis no en contro da psicol ogia com a edu cação. 1 ed. São Paulo: Casa do Psicólogo, 2007, p. 117-143.

MARTINEZ, A. Inclusão escolar: desafios para o psicólogo. In: MARTINEZ, A .(org). M. Psicologia Escolar e compromisso social. Campinas, Alínea, 2005, p. 95-114.

MENDONZA, C.E.F. Estudo exploratório sobre a atuação dos psicólogos escolares que trabalham com populações especiais em M ato Grosso do Sul. Estudos de Psicologia, São Paulo, v. 14, n. 1, p. 71-82, 1997.

MICHELS, M.H. Paradoxos da formação de professores para a educação especial : o currículo como expressão da reiteração do modelo médico-psi cológico. Revista Brasileira de E du cação Especial, M arília, v.11, n.2, p.255-272, Mai.-Ago. 2005.

NETO, J.L.F.; PEN NA, L.M.D. Ética, clínica ediretrizes: a formação do psicólogo em tempos de avaliação de cursos. Psicologia em Estudo, Maringá, v. 11, n. 2, p. 381-390, Mai.-Ago. 2006.

NEVES, M. M. B. J. A atuação dos psicólogos escolares no Distrito Federal. In: MARINHOARAÚJO, C. M.(Org.). Psicologia E scolar: novos cenários e contextos de pesquisa, prática e formação. Campinas: Grupo Átomo Alínea, 2009. p. 55-73.

OLKIN, R.; PLEDGER, C. Can Disability Studies and Psychology Join Hands? A merican Psychologist. v. 54, n. 4, p. 296-304, 2003.

PAPARELLI, R.B.; N OGUEIRA-MARTINS, M.C.F. Psicólogos em Formação: Vivências e Demandas em Plantão Psicológico. Psicologia Ciência eProfissão, v. 27, p. 64-79, 2007.

PRIETO, R.G. Inclusão escolar: al gumas considerações sobreo conceito esuas implicações. In: MACHADO, A.M. et al. Psicologia e Direitos H umanos: educação Inclusiva, direitos humanos na escola. 1 ed. São Paulo: Casa do Psicólogo, 2005, p. 99-105.

PROENÇA, M.; SILVA, S.M.C. Psicologia na educação: políticas públicas e atuação profissional. In: IX Congresso N acional de Psicologia Escolar eEducacional, 2009, São Paulo. A nais. São Paulo: ABRAPEE, p. 118.

ROSAS, P., ROSAS, A.,; XA VIER, I.B. Quantos e quem somos? In: CFP (Org.). Q uem é o psicól ogo brasileiro. 1 ed. São Paulo: Edicon, 1988, p. 32-48. 
SANTA CATARINA. Secretaria de Estado da Educação, Ciência e Tecnologia. Fundação Catarinense deEducação Especial. Coordenador Sergio Otavio Bassetti. Política de educação especial no Estado de Santa Catarina. FCEE. São José, 52 p., 2006.

SILVA, M.V.O. A psicologia, os psicólogos e a luta pelos direitos humanos: da reflexão à ação. In: MACHADO, A.M. et al. Psicologia edireitos humanos: educação inclusiva, direitos humanos na escola. 1 ed. São Paulo: Casa do psicólogo, 2005, p. 13-37.

SIMÃO, L.M. Entrar na psicologia, encontrar os outros. Ser na Psicologia: diálogos sobre a profissão. Revista do Departamento dePsicologia-UFF, v. 19, n. 2, p. 477-500, Jul.-Dez. 2007.

SOUZA, B.P. (Org.). O rientação à queixa escolar. 1 ed. São Paulo: Casa do Psi cólogo, 2007a.

SOUZA, M.P.R. de. Prontuários revelando os bastidores do atendimento psicológico à queixa escolar. In:SOUZA , B.P. O rientação à queixa escol ar. 1ed. São Paulo: Casa do Psicólogo, 2007b, p. 27-58.

VIVARTA, V. (Coord.) M ídia e deficiência. SérieDiversidade, v. 2. Brasília: Andi - Agência Nacional dos Direitos da Infâncial Fundação Banco do Brasil, 2003.

WITTER, G.P.; FERREIRA, A.A. Formação do Psicólogo hoje. In: CFP. P sicólogo brasileiro: construção de novos espaços. 2 ed. Campinas: Alínea, 2005, p. 15-40.

WITTER, G.P. et al. Formação eestágio acadêmico em psicologia no Brasil. In: CFP.P sicólogo brasileiro: construção denovos espaços. 2 ed. Campinas: Alínea, 2005, p. 41-70.

ZANELLA , A.V. Reflexões sobrea atuação do(a) psicólogo(a) em contextos deescolarização formal. Psicologia ciência e profissão, v. 23, n. 3, p.68-75, 2006.

Recebido em: 26/ 09/ 2009

Reformulado em: 22/ 03/2010

A provado em: 08/ 07/ 2010 